\title{
Incidence and Risk Factors of Sports Injuries Among National Competitive Deadlifters
}

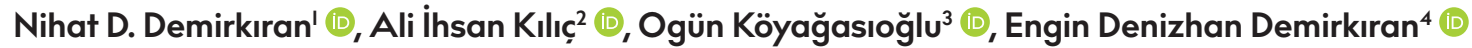 \\ 'Department of Orthopedics and Traumatology, Kütahya Health Sciences University School of Medicine, Evliya Çelebi Education and \\ Research Hospital, Kütahya, Turkey \\ 2Department of Orthopedics and Traumatology, Siirt Training and Research Hospital, Siirt, Turkey \\ ${ }^{3}$ Department of Sports Medicine, Kayseri City Training and Research Hospital, Kayseri, Turkey \\ ${ }^{4}$ Department of Urology, Șırnak State Hospital, Șırnak, Turkey
}

ORCID iDs of the authors: N.D.D. 0000-0002-0724-9672; A.I.K. 0000-000I-749I-6044; O.K. 0000-0003-35II-2750; E.D.D. 0000-0002-002I5402.

Cite this article as: Demirkıran ND, Kılıç Ai, Köyağasıŏlu O, Denizhan Demirkıran E. Incidence and Risk Factors of Sports Injuries Among National Competitive Deadlifters. Cyprus J Med Sci 202I; 6(I): 44-9.

BACKGROUND/AIMS

The purpose of this study is to evaluate the injury incidence and potential injury risk factors related to deadlifting exercises.

\section{MATERIAL and METHODS}

A total of 50 national deadlift contestants participated in this study. All 50 participants were enquired about demographics, training routines and injury characteristics before the competition via face-to-face interviews. The potential risk factors for common sports injury and deadlift-related injury were evaluated.

\section{RESULTS}

Twenty-one participants (42\%) sustained any kind of sports injury in the preceding year. Ten participants had injuries related to deadlifting exercises. The most injured body parts during training were the lumbopelvic area $(n=15)$, shoulder $(n=12)$, and knee $(n=4)$. All 10 athletes who had deadlift-related injuries described complaints over the lumbopelvic area. While all predictors were statistically insignificant in univariate analysis, stretching time was significantly different in multivariate analysis between the injured and non-injured groups of competitors $(p=.039)$. As the stretching time increased, the probability of injury risk also increased.

\section{CONCLUSIONS}

All deadlift-related injuries were on the lumbopelvic area. The stretching time was significantly different between the injured and non-injured groups. Every athlete who performed stretches for more than $15 \mathrm{~min}$ had deadlift-related lumbopelvic injuries. These results provide useful information for physicians, therapists, and trainers in planning warm-up routines for exercise programs.

Keywords: Deadlift, strength training, weightlifting, injuries, stretching

\section{INTRODUCTION}

Deadlift exercise is a multi-joint resistant exercise that consists of lifting the barbell from the ground to thigh level and slowly lowering the weight to the starting position. Together with squat and bench press exercises, deadlifting is also a part of powerlifting competitions. Deadlifting is gaining popularity as one of the most compound exercises that involves the thigh, hip, back, and core muscles (I). Recent studies have shown the beneficial effects of deadlifting for back pain (2). In addition, deadlifting may help develop muscular power (3) and improve lower body strength (4). However, deadlifting is frequently associated with an increased risk for injury. Most athletes tend to refrain from deadlifting because of their fear of injury. Nonetheless, the injury rates of deadlifting remain unclear. Few researchers have addressed the injury incidence and risk factors, mostly using data obtained from online forms (5). Prior studies were online questionnaires, which are known to have limitations compared with face-to-face surveys (6). In this study, we collected data directly from competing athletes via face-to-face interviews before a national deadlifting contest. The purpose of this study is to evaluate the injury incidence and potential injury risk factors related to deadlifting exercises. 


\section{MATERIAL and METHODS}

Data used in this cross-sectional study were obtained through face-to-face interviews with the contenders before a national deadlifting contest. All athletes performed conventional deadlift exercise during the competition. Conventional deadlift exercise was performed by bending forward at the knees and grabbing the loaded barbell from the ground, followed by lifting the barbell from the ground to thigh level. When the back and torso of the athletes were straight and in erected position, the barbell was slowly lowered to the starting position.

All athletes competing in the contest were enquired before the competition at the registry desk. As the official competition committee agreed and gave permission to our study, Ethical Committee report was not taken additionally. The authors directly explained and provided detailed information to participants regarding the questionnaire. All 50 participants of the contest filled in the survey. The potential risk factors for common sports injury and deadlift-related injury were evaluated.

An injury was defined as a condition of pain or physical impairment that affected the training of athletes in terms of total withdrawal from routine training more than I week, modification of training intensity or duration for 2 weeks, or referral to health care for any musculoskeletal problem as described previously (3).

Demographic data of athletes, including education levels and occupational environment, were assessed. The athletes were also enquired about the use of any kind of dietary supplement and any special equipment during deadlift trainings (i.e., weight belt). The participants were enquired about their weight training experience, training frequency in a week, regular guidance by a personal trainer, total training duration, deadlift experience, deadlift frequency in a week, deadlift training duration, and the mean and maximum deadlift training weights. In addition, each athlete was enquired about the warm-up, stretching, and cooldown exercise characteristics.

Regarding injury evaluation, the participants were asked to report whether they had experienced any injuries during train-

\section{Main Points:}

- Our study showed that the injuries in our competitive deadlifter athletes are similar to that of other weight training sports.

- Injuries occurred most commonly in the lumbopelvic area, shoulder, and knee.

- $\quad$ Athletes reported "poor technique/posture," followed by "excessive weight" as the most common causes of injuries.

- We found that stretching time was significantly different between the injured and non-injured groups of competitors $(p=.039)$.

- As the stretching time increased, the probability of injury risk also increased. These results suggest that the type and duration of stretching prior to exercise should be considered cautiously by trainers and athletes if they wish to minimize the rate of sports injuries and deadlift-related injuries. ings and particularly, any injuries related to deadlift trainings in the preceding year. Location of the injury, referral to any kind of health care professional, and treatment modality were assessed. The athletes were also asked whether they felt any discomfort in that body area before the injury, and their opinion on the probable cause of their injury (excessive weight/posture or technique error/fatigue/recurrence of old disability/insufficient rest/poor nutrition). The complete questionnaire form is shown in Appendix.

\section{Statistical Analysis}

The study was completed by 50 people who provided oral consent to participate in the study. The representative power of the sample was calculated using post-hoc power analysis. In this analysis, the injury rate of our study was calculated as $p=.20$, and according to the studies in the deadlift population, the rate of injury was calculated as $p=.40(95 \% \mathrm{Cl}, 0.30-0.50)$ and post-hoc power $87.2 \%$ when $\alpha=.05$. Predictors that may affect deadlift injury were first analyzed using univariate tests. Student's t-test and Mann-Whitney $U$ tests were used for analyzing arithmetic means. Fisher's exact test and Kolmogorov-Smirnov $Z$ tests were used for analyzing frequency. Injury status while performing deadlift movement in the two groups defined as non-injured and injured was analyzed using binary logistic regression (BLR). For performing BLR analysis, the model was first examined using Hosmer and Lemeshow test and if appropriate, the analysis was performed.

\section{RESULTS}

Fifty participants ( 6 women/44 men) above the age of 18 years were included in this study. More than half of our participants were university students, and only 5 athletes had a physically demanding job. Assessment of 33 athletes who received nutritional support revealed that the most preferred support types were whey protein and creatine pills. Demographic characteristics of the athletes included in our study are presented in Table I.

Table 2 summarizes the data about training characteristics of the participants. Only 10 athletes routinely trained with a personal trainer, whereas 40 athletes did not have regular training guidance. Most of the athletes (62\%) performed deadlifting exercises 2 days a week. Nearly one-third of all participants preferred using a weight belt during deadlift exercises. Athletes mostly preferred full body exercises (36\%) and dynamic stretching $(36 \%)$ as warm-up procedures. None of the athletes preferred static stretching as a warm-up procedure.

No injury occurred during the competition. According to our questionnaire results, 21 participants sustained any kind of sports injury in the preceding year. Ten injuries were related to deadlifting exercises. The most injured body parts during training were the lumbopelvic area $(n=15)$, shoulder $(n=12)$, and knee $(n=4)$. Regarding deadlift-related injuries, 10 athletes described complaints over the lumbopelvic area. Referral to a health care professional was necessary for 14 athletes, and the most common diagnosis was "paravertebral muscle sprain" ( $n=8)$, followed by "rotator cuff injury" ( $n=5)$. One athlete was operated for meniscus tear. Fourteen athletes stated that they felt discomfort in that body area before the injury. When the participants were assessed for their opinion on the probable cause of their injury, II athletes stated "poor technique/posture" as the most proba- 
ble cause, while 5 athletes reported "excessive weight" as the probable cause. All predictors were statistically insignificant in univariate analysis (Table 3). However, in multivariate analysis, stretching time was significantly different between the injured and non-injured groups of competitors. Statistical analysis revealed that as the stretching time increased, the probability of injury risk also increased (Table 4).

\section{DISCUSSION}

This study aimed to investigate the training characteristics of competitive deadlifters and define the internal or external risk factors predisposed to sports injuries. Our findings showed that the most commonly injured body parts were the back $(n=14)$ and shoulder $(n=I I)$. Previous studies on injury rates of weight training athletes also showed that the back and shoulder area are the most common injury sites. $(5,7-12)$. Although we performed this study in athletes who participated in the national deadlifting contest, only $47 \%(10 / 21)$ of the injuries were related to deadlifting. All deadlifting-related injuries $(n=10 / 10)$ occurred in the lumbopelvic area. During the execution of conventional deadlift movement, high axial compression forces apply on the lumbar spine and increases progressively from LI to L5. The high compressive force could be the main reason for the high rates of lumbopelvic area injuries (I3). Deadlifters not only train in deadlift movement, but also perform other compound movements such as powerlifting, Olympic weightlifting, and CrossFit as part of their strength training routine. Their routine mostly includes bench press, overhead press, clean, and different types of squats, which are similar to that in other weightlifting sports.

\begin{tabular}{|c|c|}
\hline \multicolumn{2}{|l|}{ Sex, n (\%) } \\
\hline Male & $44(88.0)$ \\
\hline Female & $6(12.0)$ \\
\hline Age (mean $\pm S D, y)$ & 24. $1 \pm 6.2$ \\
\hline Height (mean $\pm S D, c m)$ & $175.8 \pm 7.6$ \\
\hline Weight (mean $\pm S D, k g)$ & $82.2 \pm 15.7$ \\
\hline Body mass index (mean $\left.\pm S D, k g / m^{2}\right)$ & $26.5 \pm 4.2$ \\
\hline \multicolumn{2}{|l|}{ Level of education, $n(\%)$} \\
\hline High school & $7(14.0)$ \\
\hline University student & $33(66.0)$ \\
\hline Higher education or college & $10(20.0)$ \\
\hline \multicolumn{2}{|l|}{ Working style, n (\%) } \\
\hline Office work & $45(90.0)$ \\
\hline Other physical occupation & $5(10.0)$ \\
\hline \multicolumn{2}{|l|}{ Getting nutritional support } \\
\hline Yes & $33(66.0)$ \\
\hline No & $17(34.0)$ \\
\hline \multicolumn{2}{|l|}{ Getting nutrient type, n (\%) } \\
\hline BCAA & $18(36.0)$ \\
\hline Whey & $12(24.0)$ \\
\hline Creatine & $18(36.0)$ \\
\hline Vitamin & $2(4.0)$ \\
\hline
\end{tabular}

In particular, clean, bench press, and overhead press exercises apply a high rate of stress to the shoulder joint $(I 1,12,14)$. Anatomically, the shoulder joint is not a weight-bearing joint in hu-

\section{TABLE 2. Athlete characteristics}

Duration of participation in deadlifting, $n(\%)$

$<6$ months

$19(38.0)$

$6-<12$ months

$7(14.0)$

$1-<2$ years

9 (18.0)

$\geq 2$ years

$15(30.0)$

Deadlifting frequency, $\mathrm{n}(\%)$

I day/week

$14(28.0)$

2 days/week

31 (62.0)

$\geq 3$ days/week

$5(10.0)$

Deadlifting duration, $\mathrm{n}(\%)$

$<10$ min

7 (14.0)

10-20 min

$13(26.0)$

20-30 min

$18(36.0)$

$\geq 30$ minutes

$12(24.0)$

Deadlift weight (mean $\pm S D, k g)$

$141.0 \pm 42.4$

Deadlift weight maximum (mean $\pm S D, k g)$

$182.3 \pm 50.9$

Warm-up duration, n (\%)

$<5$ min

$5(10.0)$

5-10 min

$12(24.0)$

$10-15 \mathrm{~min}$

$13(26.0)$

$\geq 15 \mathrm{~min}$

$20(40.0)$

Stretching duration, $\mathrm{n}(\%)$

$<5$ min

$5-<10 \mathrm{~min}$

$12(24.0)$

$10-<15 \mathrm{~min}$

$10(20.0)$

$\geq 15 \mathrm{~min}$

Cooling duration, $n(\%)$

$<5$ min

$24(48.0)$

5-10 min

$16(32.0)$

$10-15 \mathrm{~min}$

$\geq 15 \mathrm{~min}$

Weight belt use, $n(\%)$

No/rare

Always/often

$32(64.0)$

Participation in another sport, $\mathrm{n}(\%)$

No

$19(38.0)$

Yes

Sports injury, n (\%)

No

$29(58.0)$

Yes

2I (42.0)

Deadlifting injury, n (\%)

No

$40(80.0)$

Yes

$10(20.0)$ 
TABLE 3. Case of injury in deadlift sport by various characteristics

\begin{tabular}{|c|c|c|c|}
\hline & \multicolumn{2}{|c|}{ Injured, $\mathbf{n}$} & \multirow[b]{2}{*}{$P$ value } \\
\hline & No & Yes & \\
\hline Age, $y$, mean $\pm S D$ a & $24.1 \pm 5.7$ & $24.1 \pm 8.2$ & $2 \mathrm{t}=.023, P=.982$ \\
\hline Sex, $n$ & & & $X 2$ FET, $P=.656$ \\
\hline Male & 35 & 9 & \\
\hline Female & 5 & । & \\
\hline Body mass index (mean $\left.\pm S D, k g / m^{2 a}\right)$ & $26.1 \pm 3.7$ & $27.9 \pm 5.7$ & $7 t=1.256, P=.215$ \\
\hline Working style, $n$ & & & $X 2$ FET, $P=.258$ \\
\hline Office work & 37 & 8 & \\
\hline Other work & 3 & 2 & \\
\hline Duration of participation, $n$ & & & $K S Z=0.78, P=.581$ \\
\hline$<6$ months & 13 & 6 & \\
\hline $6-<12$ months & 7 & 0 & \\
\hline $1-<2$ years & 8 & I & \\
\hline$\geq 2$ years & 12 & 3 & \\
\hline Deadlifting frequency, $\mathrm{n}$ & & & $K S Z=0.07 I, P=1.00$ \\
\hline I day/week & ॥ & 3 & \\
\hline 2 days/week & 25 & 6 & \\
\hline$\geq 3$ days/week $b$ & 4 & । & \\
\hline Deadlifting duration, $n$ & & & $K S Z=0.354, P=1.00$ \\
\hline$<10$ min & 6 & । & \\
\hline $10-<20 \mathrm{~min}$ & 9 & 4 & \\
\hline $20-<30 \mathrm{~min}$ & 16 & 2 & \\
\hline$\geq 30 \mathrm{~min}$ & 9 & 3 & \\
\hline Deadlift weight (mean $\pm S D, k g)$ & $\begin{array}{c}141.5 \pm \\
36.1\end{array}$ & $\begin{array}{c}139.0 \pm \\
64.2\end{array}$ & $\begin{array}{c}M W U= \\
0.329, P=.747\end{array}$ \\
\hline Weight belt use, $n$ & & & $\mathrm{X} 2 \mathrm{FET}, \mathrm{P}=.722$ \\
\hline No/rare & 16 & 3 & \\
\hline Always/often & 24 & 7 & \\
\hline Warm-up duration, $\mathrm{n}$ & & & $K S Z=0.707, P=.699$ \\
\hline$<5 \mathrm{~min}$ & 3 & 2 & \\
\hline $5-<10 \mathrm{~min}$ & ॥ & । & \\
\hline $10-<15 \mathrm{~min}$ & 12 & । & \\
\hline$\geq 15 \mathrm{~min}$ & 14 & 6 & \\
\hline Stretching duration, $\mathrm{n}$ & & & $K S Z=1.131, P=.155$ \\
\hline$<5 \mathrm{~min}$ & 20 & 4 & \\
\hline $5-<10 \mathrm{~min}$ & ॥ & । & \\
\hline $10-<15 \mathrm{~min}$ & 9 & । & \\
\hline$\geq 15 \mathrm{~min}$ & 0 & 4 & \\
\hline Cooling duration, $n$ & & & $K S Z=0.778, P=.581$ \\
\hline$<5$ min & 17 & 7 & \\
\hline $5-<10 \mathrm{~min}$ & 16 & 0 & \\
\hline $10-<15 \mathrm{~min}$ & 5 & । & \\
\hline$\geq 15 \mathrm{~min}$ & 2 & 2 & \\
\hline $\begin{array}{l}\text { at-test, } \text { 'l person } 7 \text { days/week, all other } \\
\text { test, KSZ: Kolmogorov-Smirnov Z, } \\
\text { MWU: Mann-Whitney U }\end{array}$ & rs 3 day & week, $\mathrm{F}$ & FET: Fisher's exact \\
\hline
\end{tabular}

\begin{tabular}{|c|c|c|c|c|c|}
\hline & & & & \multicolumn{2}{|c|}{$\begin{array}{l}95 \% \text { C.I. } \\
\text { for EXP(B) }\end{array}$} \\
\hline & B & $P C$ & Jdds Ratio & Lower & Upper \\
\hline Age, years & -0.035 & .663 & 0.965 & 0.823 & 1.132 \\
\hline $\mathrm{BMl}, \mathrm{kg} / \mathrm{m}^{2}$ & 0.130 & .343 & 1.139 & 0.871 & 1.489 \\
\hline Sex (Ref. Female) & -0.902 & .668 & 0.406 & 0.007 & 25.094 \\
\hline Occupation (Ref. Other works) & -2.198 & .161 & 0.111 & 0.005 & 2.405 \\
\hline Weight belt (Ref. uses) & -1.125 & .342 & 0.325 & 0.032 & 3.308 \\
\hline Nutritional support (Ref. taking) & -0.157 & .874 & 0.854 & 0.122 & 5.973 \\
\hline Other sports (Ref. participating) & -0.037 & .971 & 0.964 & 0.130 & 7.146 \\
\hline $\begin{array}{l}\text { Duration of deadlifting } \\
\text { participation }\end{array}$ & -0.278 & .567 & 0.757 & 0.292 & 1.964 \\
\hline Deadlifting times/week & -0.184 & .545 & 0.832 & 0.459 & 1.509 \\
\hline Deadlift weight mean, $\mathrm{kg}$ & -0.006 & .680 & 0.994 & 0.966 & 1.023 \\
\hline Warm-up duration & -0.426 & .445 & 0.653 & 0.219 & 1.947 \\
\hline Stretching duration & 1.405 & .039 & 4.077 & 1.073 & 15.487 \\
\hline Cooling duration & -0.230 & .714 & 0.794 & 0.231 & 2.727 \\
\hline Constant & 0.199 & .965 & 1.220 & & \\
\hline
\end{tabular}

Hosmer and Lemeshow test: $X 2=7.64, P=.470$

a. Variable(s) entered in step I-Continues variables: age, BMl, deadlift mean weight; ordinal variables: deadlift participation, deadlift duration/ week, warm-up, stretching, cooling duration; categorical variables: participation in other sports, use of weight belt, sex, occupation, and nutritional support.

mans; Kolber et al. (14) suggested that the high load caused by exercises makes shoulder joint susceptible to injury. Bench press and overhead press movements also place the shoulder in inappropriate positions, such as abduction and end range external rotation; these positions put additional risk on the shoulder joint. These conditions could be the reason behind the high rate of shoulder injuries in our group.

During the pressing phase of compound lift movements, especially during overhead movements, athletes may lose the correct form of exercise, and this could place the lumbar spine in an extreme lordotic position. Extreme lordotic position could lead to training-related back injuries even if athletes do not execute isolated back exercises (8).

According to our questionnaire results, stretching time was the only significantly different variable between the injured and non-injured competitors ( $p=.039$ ). Inconsistent results have been reported on the preventive effects of stretching on sports injuries. Several authors have suggested that stretching has a beneficial effect on sports injury prevention, and a proper warm-up should be performed prior to athletic performance to decrease sports injury rates.(15-20) Conversely, numerous reviews conclude that there is no sufficient evidence on the preventive effects of stretching.(2I-23) It increases range of motion (ROM), tendon compliance, and blood flow and decreases muscle stiffness. Although stretching is an important part of warm-up procedure, the type and duration of stretching should be considered cautiously. We offer two possible mechanisms on the predisposing effects of stretching in strength training athletes. 
First, weightlifting requires maximal performance and pushes athletes to their limits. However, impaired maximal muscular performance due to stretching has been reported in previous studies $(16,19,24-26)$. Stretching-induced force decrease is duration dependent. It has been shown that the longer the stretch duration, the greater the force reduction $(18,20,26)$. Longer duration of stretching exercises (above 45-90 seconds) (26) and static stretching seem to cause performance impairments more often than dynamic stretching (24). According to our findings, as the stretching time increased, the probability of injury risk also increased. Maximal force and performance reduction could impair protective core muscle contraction that provides lumbar stabilization, thus leading to lumbar region injuries $(27,28)$. Our study focused on competitive deadlifters who attempt to lift the maximal load for one repetition by producing maximal strength. During deadlifting, the L4/L5 mean compression value was 17 $192 \mathrm{~N}$, and L4/L5 mean moments value was 988.3 N.m. (29). Although different lifting techniques such as sumo style deadlift seem to reduce these forces by $10 \%$ (29), these forces still apply a very high load on the lumbar region. Thus, core and lumbar stability are essential for proper load balance within the spine and to provide appropriate kinetic chain. The absence of core and lumbar stability could lead to tendon, ligament, and endplate injuries (28-30).

Secondly, reduced spinal excitation due to stretching exercises is proposed to be the reason for increased ROM and decreased muscle stiffness. Increased ROM and decreased stiffness may be important for preventing muscle and tendon injuries, as it provides resistance to stretch. However, longer muscles and reduced excitability can impair protective reflexes. Muscle spindle sensitivity reduces because of the reduced activity of large diameter afferents caused by repeated stretching (3I-33). Any reduction in muscle spindle reflex can be dangerous and predispose injuries in athletes when having such high loads on the spine while lifting.

We collected data directly from each competing athlete via face-to-face interviews before a national deadlifting contest. The data of previous studies on injury rates of strength training athletes were collected via online questionnaires $(5,10)$, which are known to have limitations compared with face-to-face surveys. Online or telephone interviews might not reach every athlete. For instance, e-mail invitations might be deleted before they are read, athletes' telephone numbers might be wrong, or their e-mail addresses might be inactive $(34,35)$. Importantly, online or telephone interviews might have a selection bias compared with face-to-face interviews, as certain athletes may answer more questions than the others. As our face-to-face interview allowed us to collect data from each participant, we have not missed any data.

There are some limitations to our study. First, as the study included only athletes who participated in the national deadlifting contest, the number of participants was low. This might have affected the results to a certain extent. Second, injuries were not categorized by their severity. Therefore, we were unable to analyze the relationship between risk factors and severity of injuries. Third, as the participants were not enquired about their leisure time activity and risk factors related to their work, the effects of these factors could not be investigated.
The injury incidence among athletes participating in national deadlifting contest was $42 \%$. The most commonly injured body parts were the shoulder, lumbopelvic area, and knee. All deadlift-related injuries were on the lumbopelvic area. The stretching time was significantly different between the injured and non-injured groups of competitors $(p=.039)$. Every athlete who performed stretches for more than $15 \mathrm{~min}$ had deadlift-related lumbopelvic injuries. These results provide useful information in defining the predisposing factors of sports injuries in deadlifters.

\section{Ethics Committee Approval: N/A}

Informed Consent: The participants were informed about the study and their consent was obtained.

Peer-review: Externally peer-reviewed.

Author contributions: Concept - N.D.D., E.D.D.; Design - N.D.D., E.D.D.; Supervision - N.D.D.; Resource - N.D.D., E.D.D.; Materials - N.D.D., E.D.D.; Data Collection and/or Processing - N.D.D., E.D.D., A.I.K. O.K.; Analysis and/or Interpretation - A.I.K., O.K.; Literature Search - N.D.D., A.I.K., O.K.; Writing N.D.D., A.I.K., O.K.; Critical Reviews - N.D.D., A.I.K., O.K., E.D.D.

Conflict of Interest: Authors have no conflicts of interest to declare.

Financial Disclosure: The authors declared that this study has received no financial support.

\section{REFERENCES}

I. Piper TJ, Waller MA. Variations of the Deadlift. Strength Cond J 200l; 23(3): 66-73. [Crossref]

2. Berglund L, Björn A, Hellqvist J, Michaelson P, Aasa U. Which Patients With Low Back Pain Benefit From Deadlift Training? J Strength Cond Res 2015; 29(7): 1803-II. [Crossref]

3. Swinton PA, D. Stewart A, Keogh JWL, Agouris I, Lloyd R. Kinematic and kinetic analysis of maximal velocity deadlifts performed with and without the inclusion of chain resistance. J Strength Cond Res 20II; 25(II): 3163-74. [Crossref]

4. Stock MS, Thompson BJ. Sex comparisons of strength and coactivation following ten weeks of deadlift training. J Musculoskelet Neuronal Interact 2014; 14(3): 387-97.

5. Strömbäck E, Aasa U, Gilenstam K, Berglund L. Prevalence and Consequences of Injuries in Powerlifting: A Cross-sectional Study. Orthop J Sport Med 2018; 6(5): I-10. [Crossref]

6. Bowling A. Mode of questionnaire administration can have serious effects on data quality. J Public Health (Bangkok) 2005; 27(3): 281-91. [Crossref]

7. Keogh J, Hume PA, Pearson S. Retrospective Injury Epidemılogy Of One Hundred One Competitive Oceania Power Lifters: The Effects Of Age,Body Mass, Competitive Standard, And Gender. J Strength Cond Res 2014; 38(2): 497-520.

8. Weisenthal BM, Beck CA, Maloney MD, DeHaven KE, Giordano BD. Injury rate and patterns among crossfit athletes. Orthop J Sport Med 20|4; 2(4): 2325967||453|I77. [Crossref]

9. Aasa U, Svartholm I, Andersson F, Berglund L. Injuries among weightlifters and powerlifters: A systematic review. Br J Sports Med 20I7; 5I(4): 2II-9. [Crossref]

10. Mehrab M, de Vos RJ, Kraan GA, Mathijssen NMC. Injury Incidence and Patterns Among Dutch CrossFit Athletes. Orthop J Sport Med 2017; 5(12): I-13. [Crossref]

II. Montalvo AM, Shaefer H, Rodriguez B, Li T, Epnere K, Myer GD. Retrospective injury epidemiology and risk factors for injury in CrossFit. J Sport Sci Med 2017; 16(I): 53-9.

12. Bengtsson $V$, Berglund $L$, Aasa $U$. Narrative review of injuries in powerlifting with special reference to their association to the squat, 
bench press and deadlift. BMJ Open Sport Exerc Med 2018; 4(I): I-8. [Crossref]

13. Eltoukhy M, Travascio F, Asfour S, Elmasry S, Heredia-Vargas H, Signorile J. Examination of a lumbar spine biomechanical model for assessing axial compression, shear, and bending moment using selected Olympic lifts. Neuroimage 2016; 13(3): 210-9. [Crossref]

14. Kolber MJ, Beekhuizen KS, Cheng MSS, Hellman MA. Shoulder Injuries Attributed To Resistance Training: A Brief Review. J Strength Cond Res 2010; 24(6): 1696-704. [Crossref]

15. Safran MR, Seaber A V., Garrett WE. Warm-Up and Muscular Injury Prevention An Update. Sport Med 1989; 8(4): 239-49. [Crossref]

16. Witvrouw E, Mahieu N, Danneels L, McNair P. Stretching and injury prevention: An obscure relationship. SportMed 2004; 34(7): 443-9. [Crossref]

17. Woods K, Bishop P, Jones E. Warm-up and stretching in the prevention of muscular injury. Sport Med 2007; 38(I0): 879. [Crossref]

18. Behm DG, Chaouachi A. A review of the acute effects of static and dynamic stretching on performance. Eur J Appl Physiol 20II; III(II): 2633-5I. [Crossref]

19. Behm DG, Blazevich AJ, Kay AD, McHugh M. Acute effects of muscle stretching on physical performance, range of motion, and injury incidence in healthy active individuals: A systematic review. Appl Physiol Nutr Metab 2015; 4I(I): I-II. [Crossref]

20. Kay AD, Husbands-Beasley J, Blazevich AJ. Effects of Contract-Relax, Static Stretching, and Isometric Contractions on Muscle-Tendon Mechanics. Med Sci Sports Exerc 2015; 47(10): 218I-90.[Crossref]

21. Thacker SB, Gilchrist J, Stroup DF, Kimsey CD. The Impact of Stretching on Sports Injury Risk: A Systematic Review of the Literature. Med Sci Sports Exerc 2004; 36(3): 37I-8. [Crossref]

22. McHugh MP, Cosgrave $\mathrm{CH}$. To stretch or not to stretch: The role of stretching in injury prevention and performance. Scand J Med Sci Sport 2010; 20(2): 169-81.

23. Laversen JB, Bertelsen DM, Andersen LB. The effectiveness of exercise interventions to prevent sports injuries: $A$ systematic review and meta-analysis of randomised controlled trials. Br J Sports Med 20I4; 48(II): 87I-7. [Crossref]
24. Behm DG, Plewe S, Grage P, Rabbani A, Beigi HT, Byrne JM, et al. Relative static stretch-induced impairments and dynamic stretch-induced enhancements are similar in young and middle-aged men. Appl Physiol Nutr Metab 20II; 36(6): 790-7. [Crossref]

25. Micheo W, Baerga L, Miranda G. Basic principles regarding strength, flexibility, and stability exercises. PM R 2012; 4(II): 805-II. [Crossref]

26. Opplert J, Babault N. Acute Effects of Dynamic Stretching on Muscle Flexibility and Performance: An Analysis of the Current Literature. Sport Med 2018; 48(2): 299-325. [Crossref]

27. Cholewicki J, Pm M. Mechanical stability of the in viva lumbar spine: implications for injury and chronic low back pain Introduction pressive loads exceeding $20 \mathrm{~N}^{\prime}$ and the lumbar part of. Cbkxd Biomechnics 1996; II(I): 15. [Crossref]

28. Akuthota $\bigvee$, Ferreiro $A$, Moore T, Fredericson M. Core stability exercise principles. Curr Sports Med Rep 2008; 7(I): 39-44. [Crossref]

29. Cholewicki J, McGill SM NR. Lumbar spine loads during the lifting of extremely heavy weights. Med Sci Sports Exerc 1991; 23(I0): 117986. [Crossref]

30. Hodges PW. Core stability exercise in chronic low back pain. Orthop Clin North Am 2003; 34(2): 245-54. [Crossref]

31. Avela J, Kyröläinen H, Komi PV. Altered reflex sensitivity after repeated and prolonged passive muscle stretching. J Appl Physiol 1999; 86(4): 1283-91. [Crossref]

32. Guissard N, Duchateau J. Neural aspects of muscle stretching. Exerc Sport Sci Rev 2006; 34(4): 154-8. [Crossref]

33. Chaabene H, Behm D, Negra Y, Granacher U. Acute Effects of Static Stretching on Muscle Strength and Power: an Attempt To Clarify the Previous Caveats. Front Physiol 2019; 10: 1468. [Crossref]

34. Holbrook AL, Green MC, Krosnick JA. Telephone versus Faceto-Face Interviewing of National Probability Samples with Long Questionnaires. Public Opin Q 2003; 67(I): 79-125. [Crossref]

35. Meho LI. E-Mail Interviewing in Qualitative Research: A Methodological Discussion. J Am Soc Inf Sci Technol 2013; 64: 1852-63. 


\section{APPENDIX \\ QUESTIONNAIRE FORM ON THE INCIDENCE AND RISK FACTORS OF SPORTS INJURIES AMONG NATIONAL COMPETITIVE DEADLIFTERS}

Age:..................
Telephone:
E-mail address:
Education
Sccupation:

Weight:

Height

Nutritional support

I. Sports discipline:

- Powerlifter

- Bodybuilder

- CrossFit

- Fitness

o Other:

2. How long have you been doing weight training?

- 0-6 months

- 6-12 months

- I-2 year(s)

- More than 2 years

3. How many days do you train in a week?

4. Does a personal trainer supervise your workouts?

- Yes

- No

5. Average training duration:

- 0-30 min

- $\quad 30-60 \mathrm{~min}$

- 60-90 min

- 90-120 min

- Above $120 \mathrm{~min}$

6. How long have you been deadlifting?

- 0-6 months

- 6-12 months

- I-2 year(s)

- More than 2 years

7. How many days do you perform deadlifts in a week?

8. Do you use a weight belt?
- Always
- Often
- Rarely
- Never 
9. Average time you spend on deadlifts per day:

- 0-10 min

- $\quad 10-20 \mathrm{~min}$

- 20-30 min

- Above 30 min

10. Your deadlift weights:

Average:...................................................

Max:

II. Average warm-up time before training:

- 0-5 min

- 5-10 min

- 10-15 min

- Above $15 \mathrm{~min}$

12. Warm-up type:

- Full body exercises (running, rowing, jumping rope, etc.)

- Dynamic stretch

- Static stretch

- Exercise-specific warm-up (such as perform deadlift movement before deadlift exercise or perform squat movement before squat exercise)

- Warm-up by gradually increasing the weight up to the training weight

o Other:

13. Stretching time before training:

- 0-5 min

- 5-10 min

- $10-15 \mathrm{~min}$

- Above $15 \mathrm{~min}$

14. Cooling exercises and stretching time after training:

- $0-5 \mathrm{~min}$

- 5-10 min

- $10-15 \mathrm{~min}$

- $15 \mathrm{~min}$

15. Do you participate in any sports other than weightlifting? (football/basketball/swimming/running/ ..............)

16. How many days per week do you participate in a sport other than weight sports?

17. How many days of rest do you have in your training program?

18. Have you ever experienced injuries in the past year?

- 0

० I

- 2

- 3 or more 
19. Have you ever experienced injuries during deadlifting in the past year?

○ 0

○ I

○ 2

- 3 or more

20. Deadlift injury localization:

- Neck

- Back

- Waist

- Shoulder

- Elbow

- Wrist

o Hip

- Knee

- Ankle

o Other

21. Did you seek medical advice? If yes, what was your diagnosis?

22. Prior to the injury, did you feel any discomfort in the injured area?

23. In your opinion, the factor causing this injury was:

- Excessive weight

- Posture error

- Fatigue

- Recurrence of old injury

- Inadequate rest

- Diet plan problems 